would have left. During this interval the typhoid bacilli disappeared from their stools and urines.

One case thought by the Boston Board of Health to be typhoid fever was sent into the hospital late in convalescence for diagnosis. Repeated Widal tests were made, all of which proved to be negative, but an examination of the stools revealed paratyphoid bacilli. Clinically it was impossible to make a diagnosis in this case and the examination of the stools alone established the diagnosis. This case is not included in the series of cases reported in this article.

The stools and urines of 65 patients were examined according to the methods described above, and within ten days of their discharge from the hospital. Of this number 33 were males and 32 were females. The average length of time each patient was in the hospital was fortyone days, and the average number of days intervening between the first normal temperature and the time of discharge of the patient was nineteen days. Approximately the same duration of hospital convalescence held good for the cases shown to be carriers of typhoid. Thus cases discharged with positive stools remained in the hospital for twenty-three days with a normal temperature, and cases with positive urines for nineteen days.

Eleven, or $16.9 \%$, of the patients examined had typhoid or paratyphoid bacilli in their stools and seven, or $10.8 \%$, had typhoid or paratyphoid bacilli in their urines. Three had bacilli in both stools and urines. There were, therefore, 15 typhoid carriers among the 65 cases discharged; in other words, $23 \%$ of the cases in our series were a menace to the community at the time they left the hospital. We feel confident the number of typhoid carriers found would have been somewhat increased if four specimens of urine from each female patient had been examined instead of one specimen from each of them.

Our results are summarized in the following table:*

Total number of cases showing typhoid bacilli in stools,

Total number of cases showing typhoid para alpha bacilli in stools,

Total number of cases showing typhoid para beta bacilli in stools,

Total,

Total number of cases showing typhoid bacilli in urine,

Total number of cases showing typhoid para alpha in urine,

Total number of cases showing typhoid para beta in urine,

Total,

Total number of cases with bacilli in stools and urines, Deduct number of cases with stools and urines both positive,

Actual number of carriers,

* Two of the cases included in this series were studied very late in convalescence and in our hands the Widals done on them were very suggestive, but not positive. The hospital records show; that in the course of the disease were positive.
Number of cases with mixed infection, stools containing para alpha typhoid bacilli and urine typhoid bacilli,

Total number of stools examined,

Total number of urines examined,

CONCLUSIONS

Twenty-three per cent of a series of 65 typhoid fever patients were shown to have typhoid bacilli in their stools or urines during the ten days preceding their discharge from the Boston City Hospital.

The stools and urines of all typhoid fever patients should be examined for typhoid bacilli during the last ten days preceding their discharge from medical care.

Typhoid patients with positive stools or urines should be detained in the hospital. If at the end of ten weeks they still show typhoid bacilli, they should be allowed to leave the hospital, but should remain under the supervision of the Board of Health until they cease to be carriers. Until that is the case such typhoid distributers should have their occupations restricted; they should not be allowed to follow those pursuits which would endanger others.

These regulations are essentialy those which have been in force in Germany for some years.

\section{REMINISCENCES OF AMERICA.*}

BY MAX BOEHM, M.D., BERLIN.

Translated by J. B. HARTWELL, M.D.

Gentlemen, - - It is not my intention to give you this evening in a formal address a systematic exposition of country and people, of physicians and medicine, in the United States of America; I merely desire, quite informally, to retail to you impressions --impressions which I had the opportunity of collecting during my three years" residence in the land of " unlimited possibilities."

Our literature on America has been extraordinarily swollen in the last decade. But rarely, I assure you, are there found so many untrue estimates as in this particular literature; rarely are there so many false impressions given as in European accounts of North America. Every traveler who spends a short six weeks in that country thinks he must favor his compatriots 11 with descriptions of his travels, but at the same time he is unconscious of the difficulty of portraying a correct picture of life in the United States.

Correctly to portray America is a difficult 2 undertaking, and for several reasons. First 7 and foremost, it seems to me, because there is 7 absolutely no uniform North America, if I may 18 so put it. 'The social, the cultural, the political relations, - in short, the individual features of 3 life in America, offer an extraordinary variety. It must not be forgotten that the American population is but a conglomeration of peoples with different customs and with different con*From Berliner Klinische Wochenschrift, Aug. 24, 190\%. 
ceptions of life. From these conditions, however, there arises, with wonderful uniformity, the "American people."

In the different parts of the larger centers of North America there congregate the recently immigrated families, grouped according to nationality. Here is the German quarter; there the dirty Italian quarter; here again the Ghetto of the Russian Jew. But it takes only one generation, and presto! the son of the immigrant German or Italian or Russian Jew, of him who spoke broken English with difficulty, becomes a red-hot American patriot, who considers his belonging to the old stock, like all else that has gone before, an honor. It is astonishing what slight difficulty the moulding of these different peoples offers to the American commonwealth - astonishing when we consider, for example, how difficult it is for the Prussian state to deal with the Polish population.

What is the secret of this extraordinary system of political amalgamation? Doubtless it is the democratic spirit. Each immigrant yearns to become one of the American citizens, who votes.

The variety of the elements which make up American life does not offer the only difficulty for our critical estimate. A thing in statu nascendi is more difficult to criticise than a thing completed. America is growing, is in the process of development. In all branches of their life, Americans are experimenting, are searching for the best ways and means. While with us stability rules, over there relations change -- we might almost say - from day to day. The American system of education finds itself in a condition of rapid development of this kind.

The chief difference in the higher systems of education here and there lies in the institution of the "college." The college is something we do not know here; it is intermediate between the gymnasium and the university. When the young American leaves high school he goes to college. He does not receive there a "special" education as in our universities, but receives a further general education; for example, he is instructed in languages, mathematics, logic, philosophy. On the completion of the three or four years' college course only does the student begin his special training. He now enters the medical school or the law school. The college, gentlemen, belongs to the university, but if American university life is libeled, it is the college life that is intended.

All the special features of the American Alma Mater are derived from the college; for example, the sports, which assume so important a place in American university life, are engaged in by college students only. We read often in accounts of America that sport. plays so very important a part in the American universities that the mental development of the American suffers. Indeed, gentlemen, such accounts lead to false conclusions. Every German assumes that the American medical student, for example, instead of attending his exercises in anatomy, spends his days on the football field. But that is not true. The miedical student has nothing to do with athletics; it is the college student only, as I have said already, who engages actively in sport.

Again, the German university is devoted to special schools exclusively; the American university has two divisions: on the one hand, a school for general academic education, --the college; and on the other hand the individual special schools.

In my opinion, it is a very good idea to introduce the young students to the fundamental principles of philosophy before they begin their specialized study; and it is an open question whether we cannot learn from America in this respect. In fact, among some of the "Burgerschaft" of Hamburg the plan has been evolved of uniting with the new Hamburg University a college on the American plan. And it is due to Professor Münsterberg, of Harvard University, that a sentiment in this direction has been aroused in Hamburg. Münsterberg has strongly advocated this plan.

It is interesting that in the American college there is one department which does not exist with us, - the so-called department of physical culture. This serves in a measure as a center for the physical development of the American people. At the same time, in this school young men and women are trained to become teachers of physical culture. They learn in a systematic way the value of physical exercises, of all kinds of gymnastics, of swimming, fencing, dancing. And further, they learn methods of instructing pupils in a systematic way. From the department of physical culture there go forth annually large numbers of well-trained teachers, who contribute extraordinarily to interest in physical exercise and thereby improve the health of the whole people.

Aside from its value as a training school, the department of physical culture serves another important purpose, namely, the systematic physical development of the student. On his entrance into the university, the student has the privilege of a thorough physical examination. The results of the examination, which are ascertained by the use of exact instruments, - dynamometers, etc., - are noted on anthropometric charts. In this way it is determined whether in one direction or another the student's frame shows any defect, and then the student is advised by the director in what way, through athletics, he can overcome this defect. At definite intervals thereafter the effect of the sport he takes up is estimated by subsequent measurements.

This department at Harvard University is under the direction of a physician, Professor Dr. Sargent, who has carefully studied and elaborated the system of anthropometric mensuration.

You will admit that this system of physical development, under expert medical supervision, offers a valuable example, which is worthy the imitation of German universities. 
The purely medical education comprises a four years' course. This course is pursued at the medical school of a university. The theoretical branches, such as physics, chemistry and botany, are finished in the college; the practical work is done in the hospital.

The hospital where I had the opportunity of working for three years is the training hospital of Harvard University and is a typical American university clinic. A description of this institution may be of interest to you. The clinic is one of the oldest of American hospitals - about one hundred years old. It is not supported by the state, or by the city even, but the hospital has an endowment of its own, by means of which it meets its obligations. This endowment represents private donations.

The administrative staff of the hospital is sharply separated from the medical staff. The administration rests in the hands of a superintendent and several assistants, all of whom are physicians. The medical service is carried on in a characteristic way. In general, there are no paid medical appointees. The physicians of the hospital are physicians of the city, who give their services without renumeration, but the service is, in a certain way, secondary to private practice.

In the Massachusetts General Hospital there are associated in the "House," six internists and nine surgeons; there are three assistant surgeons also. In the Out-Patient Department are nine internists and nine surgeons. In addition there are the neurologists, the aurists, orthopedic surgeons, etc. All told, the medical service of this hospital is provided with a staff of seventy-seven physicians. Of these none lives in the hospital and their duties bring them to the hospital for but a few hours each day. The service is not permanent or continuous throughout the year, but each member of the staff takes his turn and is "on duty" for four months.

In addition to these seventy-seven physicians, there are the so-called "house-pupils," who reside in the hospital. 'These are young men who have just been admitted to practice, and in certain respects they complete their "year of practice" in this clinic. Eight of these probationers serve on the medical side and twelve on the surgical. The Massachusetts General Hospital has in all, therefore, about one hundred physicians.

You find, gentlemen, this enormous array of physicians in an American hospital. This organization of the medical service is typically democratic - American.

The system, of course, offers an opportunity to a comparatively large number of young men to acquire a medical training, but on the other hand the system has great disadvantages. In this way a good average of medical education is granted to a large number of persons, but individualities do not ripen in it. Scientific investigation suffers. This system lacks the element of the medical organization which make scien- tific achievements in Germany possible, namely, assistants. The house-pupil is still too young to do a piece of scientific research on his own responsibility; the practicing physician, on the other hand, is too much pressed with the cares of existence, so that he may not in quietness devote himself to science.

In this organization of the medical service which I have described, there is a relation of equality among the physicians rather than one of subordination, - a condition almost incomprehensible to us Germans, who are accustomed to subordination and discipline. The wonder is that with this system our American colleagues do so well.

It must be admitted that in many American hospitals the weakness of the medical organization, as sketched above, is recognized and that this recognition has led to a reform along the lines of the German system, that is, to the introduction of the continuous medical service and to the appointment of regular directors with chief and assistant physicians, and to a subordination of the one to the other. A hos-pital of this latter stamp we find in Johns Hopkins University in Baltimore, - - the very best recognized medical school in America. In my opinion it is a question of time only, when the same system will be introduced into the other American university clinics.

Here is a victory for the German view: that in the realm of educational methods, especially, the German method is becoming more and more recognized as the standard. In the institution of the exchange of professors much more may be expected in this direction.

The accomplishments of American medicine in many respects are considerable. Hospital organization, asepsis, surgical technic are subjects in which we learn much from over there. The methods of instruction, especially in the theoretical subjects of medicine, occupy a pre-eminent position and are advancing with great strides. Orthopedic surgery, in particular, many years ago won for itself recognition in America as an independent branch of medicine. Not only are there chairs of orthopedic surgery in all the larger universities, but in all the larger cities there are special orthopedic clinics. This is interesting at this time, when here in Berlin, since Hoffa's death, orthopedic surgery must fight for its continued independent existence.

That we are indebted to America for one great achievement in the medical world is too frequently forgotten, gentlemen. I mean the discovery of narcosis, which took place in the year 1846, when Morton first demonstrated the use of ether at the Massachusetts General Hospital in Boston.

The anniversary of this memorable day is celebrated at the Massachusetts Hospital each year on the sixteenth of October. At the last celebration a nonogenarian, an eye-witness of the first administration of ether, described the story of its origin. Up to the year 1846, patients were "stupefied," as the gentleman expressed 
it, with large doses of alcohol. Subsequently attention was given to the soporific influence of ether, and it was used experimentally on mice, which were placed under a bell-jar, into which at the same time ether was introduced. The mice naturally died. Similar experiments were then repeated by many medical students. There was great fear of administering ether to patients because it was generally felt that the patient would not recover from the narcosis.

Then, at the instigation of Morton, on Oct. 16, 1846, Surgeon John Collins Warren, professor of surgery in the Harvard Medical School, assumed the extraordinary responsibility of removing a lymphoma from a young man's neck, using ether as a narcotic. The narcosis was a perfect success and the chance was justified. I show you here a picture of one of the first operations when ether was used. There is no photograph extant of the actual first operation.

In spite of these individual achievements in the field of medicine, in spite of the first-class organization of certain American universities, a general criticism of the standing of the American physician cannot be very favorable.

It cannot be denied that many questionable elements exist in American medicine. There are many inferior medical schools. The great universities on the eastern seaboard which approach our German universities, such as Harvard University in Boston, Johns Hopkins University in Baltimore, and Columbia University in New York, cannot be taken unqualifiedly as the ordinary type of American universities. Besides these, there are a large number of private medical schools, which instruct their students in a very insufficient manner, where, among other things, the students, during their whole course, do not set eye upon a patient. In Washington, for example, there is a medical school where young people, clerks and others, after their day's work in an office or at their business, study medicine in the evening hours and after four years of theoretical work receive their doctor's degree. This degree, the M.D., ${ }^{1}$ is not bestowed by universities, but is generally awarded on the basis of a three-days' oral and written examination, which is given at the so-called State House, before a Board, without the candidate's being obliged to furnish evidence of his practical ability with patients.

That the American public, under such conditions, occasionally loses confidence in its physicians is not surprising. The result is a luxuriant growth of quackery. In America there is tolerance of all sorts of therapeutics. The largest contingent of quacks in the East are included in two parties: one, the so-called "osteopaths"; the second, the Christian Scientists.

The osteopaths put forward the principle that all ills of the human body are dependent on the displacements of bones, especially of luxations of the vertebræ. According to this school, the treatment of diseases - be they typhoid or

1 This statement is obviously erroneous. The writer refers evidently to the license to practice as it is conferred in Massachusetts.
?Translator.] fracture, or measles - consists in the replacement of luxated bones into their normal positions. I have here a copy of the official publication of the osteopathic school. Here you may read two interesting papers - one on the etiology and treatment of measles, and one on goiter. In the latter article, a " Doctor of Osteopathy," their official title, - describes five cases of goiter. In all five cases the goiter was the result of a displacement of the sixth intervertebral joint, or of a sprain of the first rib. With one exception the reduction of the bones resulted in perfect cure.

The second, - - a more dangerous class of quacks, - are the Christian Scientists. The fundamental principle of this remarkable sect, which depends on an amalgamation of religion and science, is the following invention of "Mother Eddy": Man is a purely spiritual being; his diseases are spiritual errors and can be cured by prayer and purification of the soul. "Mother Eddy" has given expression to this doctrine in her famous book, "Science and Health," a book, gentlemen, into the chapters of which a healthy man cannot advance beyond the tenth page it so teems with confused and tangled expressions and doctrines. Yet this book is the most read of any in the United States and has already run through four hundred thousand copies.

Christian Science has experienced an extraordinary dissemination in America, and the people who make up the following of "Mother Eddy" are well-to-do financially and are people of good social position. As proof of this may be mentioned the fact that the "Scientists" were able two years ago, to build a church in Boston that is the most beautiful in the city and cost about eight million marks.

To the dedication of this temple, "Scientists" came from all parts of America to Boston, and fortune willed that at the same time the American Medical Association should meet in Boston. This, the largest medical organization in America, to which almost all the regular physicians in North America belong, in point of attendance at the meeting was no more important than that of the "Sicientists."

The colossal growth of the "Scientists" in America has its reasons. The principal reason is a certain fondness of the American for religion. This is especially applicable to' those districts, the population of which is chiefly of Anglo-Saxon extraction. A second reason lies in the fact that in a certain class of cases, the "Scientists" obtain rapid results namely, in hysterical affections and neuroses. It is perfectly evident that patients suffering from such affections, who devoutly believe in the efficacy of prayer, can achieve a rapid cure. It is also readily understood why prayer as a therapeutic measure should be taken over by the American physicians themselves, and why Christian Science itself should become in a certain degree pseudoscientific. Such factors are actually transferred into Boston practice, and by a well-known 
internist even, Prof. R. C. Cabot, who for this purpose has associated himself with a clergyman of that city.

From what has been said, gentlemen, you see that the American profession, so far as quackery is concerned, is much more culpable than are we. For not only do their quacks outnumber ours, but there are other things which increase the Anerican physician's guilt of collusion with quacks. The American quack is no violet that blooms unseen; rather he does his work unabashed and in the open. He enjoys much the same esteem of the American public as does the legalized practitioner. To many Americans "doctor" means doctor. Whether he be a doctor of osteopathy or of Christian Science or a licensed practitioner is quite immaterial to the masses of the American people. In passing along the streets of Boston it is not uncornmon to see on one and the same house three signs: James Smith, M.I.; William Jones, D.O.; Mary Baker, D.Ch.Sc.; in other words, Doctors of Medicine, of Osteopathy, and of Christian Science live on friendly terms in adjoining apartments.

The state, for the most part, does not think of interfering for the sake of protecting its sick citizens. In this, as in most branches of the free American life, the so-called liberal principle rules: "If you are of age, help yourself, and pick out a doctor that suits you. The state feels under no obligation to give you any voucher that this is a good doctor and that a bad one."

So the licensed practitioners are forced to protect themselves, and it is to be considered in the light of a reaction from the relations $I$ have described, that the decent licensed physicians stand under much stricter professional laws and under a much higher system of professional ethics than do we. I can give you several examples: Announcements by physicians in the newspapers, - it makes no difference what the nature of the announcement, be it of residence or of a vacation or anything else, -.- in short, all connection with the press is strictly forbidden. Again, on the house of a legitimate physician you find a sinall sign only, with his name. Every title, any statement of office hours, even the announcement that the physician is a specialist in any particular line may not be made.

From these two examples you can see that the legitimate practitioners of America, - and in the larger cities they are a large majority, -.. through their own shortconings subject themselves to a higher system of ethics than do we. As is to be expected, there is a small number in the profession who do not abide by this system of ethics but make announcements on the quiet. These physicians, however, are assured of professional and social ostracism by other members of the profession.

Gentlemen, I have not been able to give you anything like a complete picture of North America, but I hope that the few points which $I$ have discussed this evening may have given you a faint idea of conditions there.

Since my return I have been approached by the younger members of our profession with the question: "Do you advise a trip to America?" The question must be answered according to the individual questioner, depending on what the particular man has in view; depending on how much he sacrifices here and on how much that is new he will acquire over there.

But one may give some general viewpoints. The following seems to me an essential point: If one leaves the Germany of to-day and visits America, he must appreciate at once that he must exchange one civilization for another civilization. "Well," you will say, "civilization is civilization." The aims of civilization can be of a uniform nature only. The more axiomatic this view appears to us, the less does it agree with fact. The American has a different ideal of civilization from us Germans. The old and worthy German standpoint is science for science's sake, art for art's sake; in a word, a thing should be sought for its own sake. That such mental efforts broaden the practical life is a secondary matter, unessential. These efforts should never be made subservient to the practical life, but should float over it. Such is the German ideal. The American is quite different. Over there the cry is: Civilization must have an aim, and this aim must be ethical, moral or social. Civilization must serve to elevate ethics and to better social relations. A civilization which opposes the rights of man, -- egalité, fraternité, liberté, which under any circumstances forces certain men into dependence and subserviency to their fellowmen; a civilization which, under any circumstances intrusts its moral sentiment to the masses is damned; so they say in America.

Looked at in this light, we may understand many phenomena of American life. In this light you can see how an artistic production like Salome might not be produced in New York; how a Gorky could obtain no hall in Boston in which to deliver his address; how dramas of European customs must be altered and given a moral before they may be presented in America.

In this light, too, it is possible to understand that it is difficult for an individual scientist to rise high, and that the man of science or of art stands far behind the banker and the merchant in social esteem. Many other examples might be cited to show that the American civilization is differently constituted from the German. Who would venture an opinion as to which is the better?

Ideals do not feed a man, and you may object that earning a living is easier over there. Gentlemen, in the larger Eastern cities, such as New York, Philadelphia, Boston and others, that is certainly not true. In Boston, on a percentage basis, there is a greater superabundance of physicians than in Berlin, and the younger members of the profession have to struggle there exactly as they do here. In the West and Middle West of America, likewise in the South, New Mexico and elsewhere, and in Western Canada, the chances of making a living are certainly better. If the difficulties which 
are laid in the path of a foreigner, rather by the profession than by the public, can be overcome, then in those places one is assured of a lucrative practice. But the western city -- don't be deceived - though it number half a million inhabitants, is an industrial village only and not a metropolis in our sense.

Taking everything into consideration, as far as emigration goes, I recommend to the profession careful thought; but with a clear conscience, I advise every one to spend a shorter or longer time in study in the land of unlimited opportunities. He will return home with a wealth of experiences.

\section{AN EPIDEMIC OF DENGUE IN THE PHILIP- PINE ISLANDS.}

BY HAROLD W. JONES, M.1.,

First Lieutenant Medical Corps, United States Army.

DURING the latter part of the year 1907 dengue became epidemic in certain parts of the Philippine Islands; at first many cases of the disease were unrecognized and were classed as malaria, typhoid, paratyphoid, etc., but later it became evident that these had been cases of dengue. The epidemic about to be described occurred in the interior of the island of Samar and was confined entirely to native troops, not a single white person having been infected. Although the disease is common enough, there are certain points about the epidemic which seem to be of value in studying its etiology and symptomcomplex.

The first case occurred in the town of Basey, Samar, situated on the seacoast seven miles below the military post of Dawa; a small detachment of Philippine scouts was at the time stationed in this town, while the main body of troops, two full companies of over one hundred men each, was garrisoned at Dawa, a wretched barrio of a few hundred native inhabitants. At this time it was learned that in Basey there had been a good many cases of "calentura," which is the appellation given by the natives to all cases of fever, and it is now supposed that dengue was then epidemic there. Two days later the detachment of ten men proceeded to Dawa, the original case of sickness not having been recognized as dengue, although later, in view of what followed, the case should have been plain enough. Two days later at Dawa a second case made its appearance and within a day or two after that three or four others. Coincident with the epidemic among the troops an epidemic broke out in the barrio of Dawa; the town was situated on low ground, by the bank of a large river, the post being located on a high, windswept ridge about three hundred yards from the outskirts of the town.

In spite of sanitary measures instituted; namely, the prevention of mosquito bites, the disease spread rapidly through the 19th Company till a total of thirty-five men had been attacked. The first eight or ten men affected in this company occupied beds in the center of the barracks, for the most part contiguous. From this center the disease spread toward either end of the barracks, and by the tenth of August, ten days after the appearance of the first case, about fifteen men in the 19th Company had come down with the disease, while up to that date the 14th Company, which occupied barracks about one hundred and fifty yards distant, had not had a single case. On that date the first case appeared in the 14th Company. In all but five men of this company came down with the disease; the fact that it practically escaped may have been due to Providence, but was probably due to some very rigid sanitary measures.

The outbreak occurred during the period in which there was a good deal of rain, and on the approach of a period of dry weather it began to diminish. During the wet period mosquitoes were very troublesome, and although the post was well policed and there was no standing water, the insects were present in large numbers. The barracks of the 19th Company were situated on the highest point of the post, seemingly an unfavorable situation for the presence of mosquitoes, while the barracks of the 14th Company were somewhat lower down and some distance away. Out of the eight white residents of the post, no one contracted dengue, but a soldier who occupied a small room in the house of the commanding officer was taken sick. This man had slept without any mosquito bar, and it is a significant fact that a second soldier who occupied a bed alongside of the first, and who habitually slept with his mosquito bar down, escaped.

In attempting to control the epidemic the sanitary precautions employed were as follows: All men in barracks were required to keep their mosquito bars around them at all times. There being no hospital at the post, all sick had to be treated in their quarters; these were screened with especial care, inspections being made at stated intervals four or five times a day to see that directions were followed. In addition it was recommended to the commanding officer of the garrison that the pass list to visit the barrio at night be suspended; this recommendation was followed also.

Medical aspect of the epidemic. - The onset, symptoms and progress of the disease were very much alike in a great majority of the cases. The onset was very sudden in some instances, a man being taken sick, perhaps, while on guard duty and having to be assisted to his quarters. Practically every case complained of severe headache, generally frontal. The next commonest symptom, which occurred in almost all the cases, was pain in the chest. Very severe pain in the back was also noted in a large number of cases. Pain in the limbs, supposed to be the commonest, indeed, the pathognomonic symptom, was comparatively rare, much to the writer's surprise. Chill was seen in a few cases, suggesting malaria. A few cases had cough as well, 